\title{
The Art of Integrating Care: Theories Revisited
}

\author{
Bengt Ahgren*
}

Nordic School of Public Health, Göteborg, Sweden

\begin{abstract}
Integration of care is high on public health agendas all around the world. The development and implementation of integrative arrangements has been promoted for more or less two decades. Despite this every so often extensive history, there are recognised needs to take research into areas yet poorly explored, which include measures and outcomes of integrated care. On the other hand, existing evidence and knowledge can probably become more ennobled and thereby contribute to a deeper understanding of the compound art of integrating of health care services. Accordingly, the aim of this article is to re-evaluate and synthesise some revisited theories for the facilitation of sustainable integrated care solutions.

This exploration shows it is important to have crucial prerequisites for integration in place: both functional and interactional conditions. This appears to be an organic process where the stakeholders go through gradual changes until the optimum level of integration as well as mutualistic interactions are established.

It could be argued that refined knowledge could be excerpted from existing research. Then again, this strategy does not exclude actions for new research in poorly explored areas. Both approaches are important for the development of sustainable integrated care.
\end{abstract}

Keywords: Integrated care, continuums of integration, determinants of development, outcome assessment.

\section{INTRODUCTION}

The WHO Ottawa Charter of 1986 emphasizes the importance of intersectoral collaboration for the promotion of health and for the delivery of welfare service adapted to the needs of the citizens [1]. All around the world models of interorganisational integration and interprofessional collaboration have been launched in line with this concluding comment. Ageing populations and increased prevalence of chronic diseases during last decades reinforce this orientation towards prevention and care that is well co-ordinated and integrated. Otherwise, patients and service users can get lost in the system, needed services are not delivered or are delayed, and the quality of care decreases [2].

Despite convincing evidence and an every so often extensive history, there are still recognised needs to take research about integrated care into areas only superficially explored [3], such as the use of qualitative measures [4] and the effects on final outcomes, like for instance on improved health [5]. On the other hand, existing evidence and knowledge can probably become more ennobled and thereby contribute to a deeper understanding of the compound art of integrating of health care services. Accordingly, the aim of this article is to re-evaluate and synthesise some revisited theories about integrated care for the facilitation of sustainable integrated care solutions.

\footnotetext{
*Address correspondence to this author at the Nordic School of Public Health, Göteborg, Sweden; Tel: + 46 (0) 316939 00;
}

Fax: +46 (0) 316917 77; E-mail: bengt.ahgren@nhv.se

\section{HITHERTO RESEARCH}

Integrated care is thus an international issue. Furthermore, there are many different approaches, and their scopes can be quite diverse. What the arrangements though seem to have in common is the purpose to counterbalance fragmented care systems; especially for the growing number of elderly patients with multiple or complex needs [6]. Some approaches aim to crossover professional and departmental boundaries, see for example Ahgren [7], while others have the objective to integrate different sectors: for example, primary and secondary health care [8]. Nevertheless, all these applications regard integrated care as a means to an end: improved health or quality of care. Integrated care can thus be defined as an approach that seeks to improve the quality of care for individual patients and service users by ensuring that services are well co-ordinated around their needs [9]. Accordingly, there is no single model of integrated care to be applied everywhere and, moreover, integrated care is not needed for all patients and service users, but must be prioritised for those who stand to benefit most [10].

The growing interest for integrated care is also reflected in research, which includes definitional issues like having a person-oriented or organisational perspective; addressed by commentators such as Gröne \& Garcia-Barbero [11], Kodner \& Spreeuwenberg [12], Hardy et al [13] and Nies [14], and a rich research literature about inter-organisational designs, e.g. teamwork and networks; see for example Gray [15], Powell [16], Alter \& Hage [17] and 6 et al [18]. Moreover, models have been validated for the assessment of integrated care performance [19-21], and development determinants, like for instance the need of mutual trust and professional 
dedication, have been distinguished [22-24]. Such diverse focus of research implies applications of theories from various scientific domains, for instance, social, behavioural, and natural science.

However, as been pointed out, despite this extensive variety of research there is still need to further explore the issue of integrated care. At the same time, there could also be a potential in re-evaluating and synthesising available research for the creation of sustainable integrated care.

\section{RECONSIDERING AND SYNTHESISING THEORIES REVISITED}

\section{Continuums of Integration}

Following the forerunners Lawrence \& Lorsch [25], the level of integration must be correlated to the degree of differentiation of services and units; a high degree of differentiation implies a high degree of integration, and vice versa, in order to fulfil demands of the receivers. Consistent with this argument, different forms of continuums have been proposed in order to explain the context of interiorganisational conditions. Hudson et al advocate a range with autonomous organisations and functions on one end, through co-operation and co-ordination, to fully integrated organisations and functions on the other end [26]. According to Konrad, integration includes different levels of intensity: informal contacts, co-operation and co-ordination, collaboration, consolidation, and full integration [27]. Furthermore, Leutz proposed a similar typology of connection degrees between providers of services: linkage, co-ordination in networks, and full integration [22]. The later mean that resources of the organisational units concerned are pooled together to form a new organisation. Whatever typology used; a high level of integration must not be interpreted as better than lower levels. The optimum level of integration varies between different services and units and depends solely on their need of integration [25]. In some cases it is necessary to merge, while in other cases integration can be limited to loosely contacts between providers of services.

These theories were adapted by Ahgren \& Axelsson into a continuum of integration to be used in a clinical context: starting with full segregation followed by linkage, coordination, co-operation, and ending up with full integration [21]. Full segregation represents the absence of any form of contacts between providers of health care. However, segregation is not a case of fragmentation, that is, a state of differentiation without required integration to achieve unity of effort. Instead, fully segregated health care implies that a sole provider is able to fulfil all the needs of a particular group of patients [28], which, in turn, equals full integration. In line with this logic, it seems appropriate to replace the continuum of Ahgren \& Axelsson with a circular path where full segregation and full integration are in the same position, see Fig. (1).

In a health care context, the stages between full segregation and linkage could be described as inter-specialty contacts founded on referrals of patients. While clinical guidelines for specific patient groups, describing what shall be done by whom and when, are an example of linkage. Co-

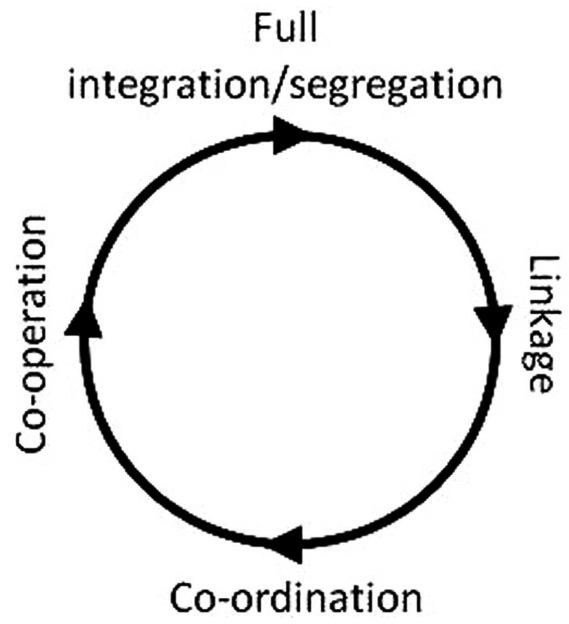

Fig. (1). Levels of interorganisational integration along a circular path.

ordination is about facilitating the transition of patients, comprised by clinical guidelines, between different health care units. Chains of Care and other types of clinical networks are included in this form of integration, but there are usually no network managers appointed. The existence of such managers would entail a higher degree of integration, that is, co-operation [21].

By applying the different forms of health care integration into a circular path instead of on a continuum, the sometimes unjustified strive to reach high positions, supported by continuums wrongly being interpreted as a kind of ranking scale of performance, is played down. Accordingly, more focus can be placed on developing the optimum state of integration, without this irrelevant influence.

\section{Symbioses between Health Care Providers}

Optimum level of inter-organisational integration is a functional precondition to achieve integration synergy [29]: an overall improved outcome than if each organisational unit was working toward the same objective separately. Health care providers must discover and recognize collaborative advantages of this kind; otherwise functional integration will be irrelevant and should be avoided [24].

Developing functional integration could be devastating when collaborative advantages are hidden or missing as professionals tend to defend their territories in contra productive ways when these are believed to be threatened by outsiders [23]. In accordance with the theory of Health Care System Ecology, inter-organisational integration founded on such disincentive conditions can turn into antagonism. That is, a condition where the interaction between two units, has an overall outcome which is less than the sum of their individual effects. Mutualism is the contrary relation: an interaction where both units derive decisive benefits. Furthermore, mutualism and antagonism could be viewed as opposite endpoints along a continuum of symbiotic effects. Commensalism can be placed on this continuum in-between antagonism and mutualism: a relationship between two health care providers where one benefits of the interaction while the other is unaffected [30]. 
Conventional inter-organisational theory, for example the work of Gray [15], Powell [16] and Alter \& Hage [17], primarily focuses on functional solutions, that is, how to organise between the organisations involved. Different kinds of environmental consequences are not always in focus; for instance which symbiotic effects evolve by implementing, for instance, integrated health care networks for coordination and provision of multidisciplinary care. Conditions of this kind seem to be of crucial importance to whether or not integrated arrangements are successfully implemented and sustainable [30].

Integration synergy appears thus to be reliant on both the functional formation and the symbiotic condition of integration. Creating the optimum level of integration between two health care units is necessary if full synergetic effects shall be obtained. The lack of mutually recognised benefits of such an arrangement could though evolve into an antagonistic interaction with a disadvantaged shift of focus: from core activities to protection of boundaries. Hence, a health care delivery network likely to be marked by contra productivity and lack of quality [30].

The top layer in Fig. (2), a combination of an optimal integration and mutualistic conditions between the stakeholders involved, is the ultimate state. The middle layer, based on commensalism, also generates added value from integration. Though, the advantages are unilateral, and thus there is a risk the unaffected part becomes disloyal over time, which, in turn, can evolve a breeding ground for an antagonistic relationship [30]. This state is illustrated by the bottom layer in Fig. (2).

\section{Integration Outcomes}

Following the classic theory of Donabedian [31], an optimum organisational structure of integration together with

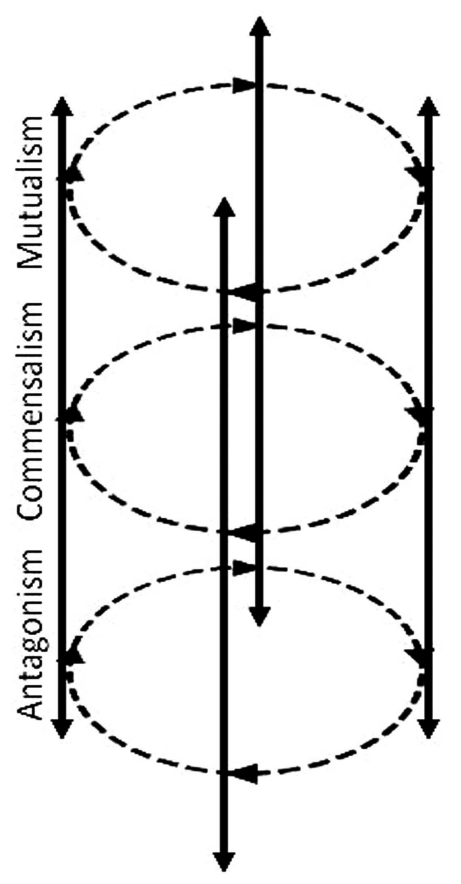

Fig. (2). Interactional conditions adapted to the interorganisational levels of integration illustrated in Fig. (1). mutualistic process conditions will facilitate best possible outcome: the purpose of integrated care. Though, outcome can be viewed from several perspectives. In this case is it important to distinguish the final outcome, that is, the one in relation to the patients and the users. Other types of outcomes, like for instance those related to managerial or professional perspectives are also important, but mostly for the understanding of the complex logic of integrated care [32]. For example, impact of managerial actions on professional condition, and of clinical performance on demand and choice among patients. Moreover, these two perspectives have so far been the prime focus of research. As been mentioned, there is accordingly a need to enlarge the knowledge about the final outcomes of integrated care: the satisfaction of the needs of the patients and the users, such as their health or recovery.

The commonly recognised faith in integrated care need thus to be accomplished by a more evidence based research on outcome issues. In that respect, there is a need to once and for all disconnect the development of integrated care from outcome-concentrated process theories with origin in the manufacturing industry. Integrated care delivery is not repetitive and founded on sequential activities, and, moreover, has not predetermined outcomes. These decisive conditions of business processes [33-35] are unachievable in the care for people with long term conditions, and even for groups of patients with short term treatment of a distinct diagnose or symptom.

\section{SYNTHESISING REMARKS}

According to the theories revisited, it is crucial to have the required prerequisites in place; both functional and interactional conditions. There is apparently no handbook for this work. It seems instead to be an organic process where the stakeholders go through continuing changes until the optimum level of integration as well as mutualistic interactions are established. Only at this complete stage is it to achieve lasting full synergy of interorganisational integration, see Fig. (3).

Conversely, if these conditions are impossible to achieve, the development work ought to be finished to avoid the evolvement of antagonistic relations between the stakeholders involved. Creating integrated care seems thus to be more of an "art" than a predictable process founded on a development work with a preset design. This kind of structural support can of course be useful when the conditions are favourable, but it is likely to be insignificant when the work is marked by suspicions among stakeholders.

Following the above analysis, it could be argued that refined knowledge could be excerpted from existing research. Then again, this strategy does not exclude actions for new research in poorly explored areas. Both approaches are important for the development of sustainable integrated care.

\section{ACKNOWLEDGEMENTS}

None declared. 

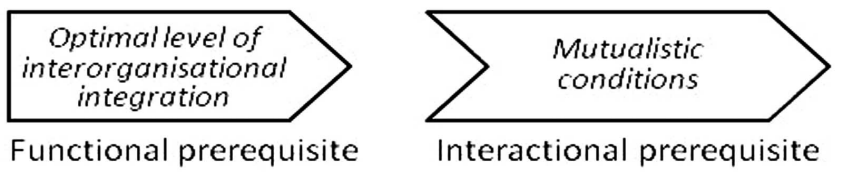

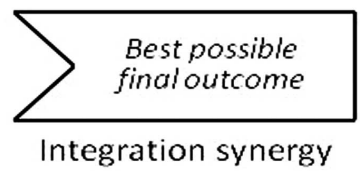

Fig. (3). Integrating care: an organic stakeholder process.

\section{CONFLICT OF INTEREST}

The authors confirm that this article content has no conflicts of interest.

\section{REFERENCES}

[1] World Health Organization. Ottawa Charter for Health Promotion. 1986 Available from: http://www.who.int/ hpr/NPH/docs/ottawa_ charter_hp.pdf [cited July 16, 2012].

[2] Berwick D. Controlling variation in health care: a consultation from Walter Shewhart. Med Care 1991; 12: 29-33.

[3] Stein KV, Rieder A. Integrated care at the crossroads - defining the way forward. Int J Integr Care 2009, Available from: http://www.ijic.org/index.php/ijic/article/view/315/ 629 [Retrieved 201216 July].

[4] Strandberg-Larsen M, Krasnick A. Measurement of integrated health care delivery: systematic review of methods and future research directions. Int J Integr Care 2009, Available from: http://www.ijic.org/index.php/ijic/ article/view/305/609 [Retrieved 201216 July].

[5] Mur-Veeman I, van Raak A, Paulus A. Comparing integrated care policy in Europe: Does policy matter? Health Policy 2008; 85: 17283.

[6] Leichsenring K. Developing integrated care and social care services for older persons in Europe. Int J Integr care 2004; Available from: http://www.ijic.org/index.php/ijic/article/view/107 /214 [Retrieved 201216 July].

[7] Ahgren B. Chains of Care: a counterbalance to fragmented health care. J Integr Care Pathways 2001; 5: 126-32.

[8] Wadmann S, Strandberg-Larsen M, Vrangbæk K. Coordination between primary and secondary healthcare in Denmark and Sweden. Int J Integr Care 2009: Available from: http://www.ijic. org/index.php/ijic/article/view /302/603 [Retrieved 2012 July 16].

[9] Lloyd J, Wait S. Integrated Care: a guide for policymakers. London: Alliance for Health and the Future 2005.

[10] Curry N, Ham C. Clinical and service integration: the route to improved outcomes. London: The King's Fund 2010.

[11] Gröne O, Garcia-Barbero M. Integrated care: a position paper of the WHO European office for integrated health care services. Int J Integr Care 2001; Available from: http://www.ijic.org/index.php/ ijic/ article/view/28/56 [Retrieved 201216 July].

[12] Kodner D, Spreeuwenberg C. Integrated care: meaning, logic, applications and implications: discussion paper. Int J Integr Care 2002; Available from: http://www.ijic. org/index.php/ijic/article/ view/67/134 [Retrieved 201216 July].

[13] Hardy B, van Raak A, Mur-Veeman I, Steenbergen M, Paulus A. Introduction. In: van Raak A, Mur-Veeman I, Hardy B, Steenbergen M, Paulus A, Eds. Integrated Care in Europe. Description and Comparison of Integrated Care in Six EU countries. Maarssen: Elsevier Gezondheidszorg 2003.

[14] Nies H. Introduction. In: Nies H, Berman P, Eds. Integrated services for older people. A Resource Book for Managers. Dublin: EHMA 2004.

[15] Gray B. Collaborating: Finding common ground for multiparty problems. San Francisco, CA: Jossey-Bass 1989.
[16] Powell W. Neither market nor hierarchy: network forms of organisations. Res Organiz Behav 1990; 12: 295-336.

[17] Alter C, Hage J. Organizations Working Together. London: Sage 1993.

[18] Goodwin N, Peck E, Freeman T. Managing networks of twentyfirst century organisations. New York, NY: Palgrave Mac-millan 2006.

[19] Lucas CV, Meterko M, Lowcock S, et al. Monitoring the progress of system integration. Qual Manage Health Care 2002; 10(2): 1-11.

[20] Browne G, Roberts J, Byrne C, Kertyzia J, Loney P. Conceptualising and validating the human services integration measure. Int $\mathrm{J}$ Integr Care 2004; Available from: http://www.ijic.org/index.php/ ijic/article/view/98/196 [Retrieved 201216 July].

[21] Ahgren B, Axelsson R. Evaluating integrated health care: a model for measurement. Int J Integr Care 2005, Available from: http://www.ijic.org/index.php/ijic/article/view /134/268 [Retrieved 201216 July].

[22] Leutz W. Five laws for integrating medical and social services: lessons from the United States and the United Kingdom. Millbank Q 1999; 77(1): 77-110.

[23] Glendinning C. Breaking down barriers: integrating health and care services for older people in England. Health Policy 2003; 65: 13951.

[24] Huxham C, Vangen S. Managing to Collaborate: the theory and practice of collaborative advantage. London: Routledge 2005.

[25] Lawrence PR, Lorsch JW. Organization and environment. managing differentiation and integration. Cambridge (MA): Harvard University Press 1967.

[26] Hudson B, Hardy B, Henwood M, Wistow G. In: pursuit of interagency collaboration in the public sector. Public Manage 1999; 1(2): 235-60.

[27] Konrad E. A Multidimensional framework for conceptualizing human Services Integration Initiatives. In: Marquart J, Konrad E, Eds. Evaluating initiatives to integrated human services. new directions for evaluation. San Francisco: Jossey-Bass 1996.

[28] Ahgren B. Whys and wherefores of Integrated health care. In: Klein LA, Neumann E, Eds. Integrated Health Care Delivery. Huntington, New York: Nova Science Publishers 2008; pp. 137-50.

[29] Lasker RD, Weiss ES, Miller R. Partnership synergy: a practical framework for studying and strengthening the collaborative advantage. Milbank Q 2001; 79(2): 179-205.

[30] Ahgren B. Mutualism and antagonism within organisations of integrated health care. J Health Organ Manag 2010; 24(4): 396411.

[31] Donabedian A. Evaluating the quality of medical care. Milbank Mem Fund Q 1966; 44(3): 166-203.

[32] Ahgren B. Creating integrated care: evaluation and management of local care in Sweden. J Integr Care 2007; 15(6): 14-21.

[33] Devenport T, Short J. The new industrial engineering: information technology and business process redesigned. Sloan Manage Rev 1990; 31: 11-27.

[34] Harrington HJ. Business process improvement: the breakthrough strategy for total quality, productivity and competitiveness. Baskerville: McGraw-Hill 1991.

[35] Hammer M, Champy J. Reengineering the Corporation: a Manifesto for a Business Revolution. London: Nicholas Brealey 1994. 